\title{
Assessment of Correlation of Radiographic Findings and Cartilage Abnormalities on MRI in Osteoarthritis Knee Patients
}

\author{
Girish Sahni ${ }^{1}$, Sanjeev Kumar', Munish Kumar Garg ${ }^{2}$, Ayush Kumar Jain ${ }^{2}$ \\ ${ }^{1}$ Associate professor, Department of Orthopedics, Govt medical college, Patiala, ${ }^{2}$ Senior resident, Department of Orthopedics, GMC Patiala, ${ }^{3}$ Junior Resident, Dept. \\ of Radio diagnosis, Govt Medical College, Patiala.
}

\section{Abstract}

Background: Osteoarthritis (OA) is a widely prevalent disease worldwide and is a major public health problem that primarily affects the elderly.The present study was undertaken to define the radiographic findings of osteoarthritis (OA) of knee joint using Kellgren-Lawrence scores and to define cartilage abnormalities on magnetic resonance (MR) imaging. Subjects and Methods: Present study was conducted on 50 patients presenting with knee pain and clinical suspicion of osteoarthritis. Antero-posterior radiographs of the knee were obtained in a weight-bearing extended position by using a standard radiographic technique. All radiographs were assigned scores by using the KellgrenLawrence scoring system.Cartilages alterations on MRI were assigned grades as follows: grade 0, normal; grade I, internal signal intensity alteration only; grade IIA, defect of cartilage of less than 50\%; grade IIB, defect of cartilage of 50\%-99\%; grade IIIA, $100 \%$ defect of cartilage with no bone ulceration; or grade IIIB, $100 \%$ defect of cartilage with subjacent bone ulceration. Radiographic and MR imaging findings were compiled as per performa and subjected to analysis using appropriate statistical tests. Results: Among 26 patients of grade 0 KL score, 6, 4, 6, 4, 4 and 2 patients had grade 0, grade 1, grade 2A, grade 2B, grade 3A and grade 3B Cartilage abnormality (On MRI) respectively. Among 8 patients of grade $1 \mathrm{~K}-\mathrm{L}$ score, 2, 2, 2 and 2 patients had grade 0 , grade $2 \mathrm{~A}$, grade $2 \mathrm{~B}$ and grade $3 \mathrm{~A}$ Cartilage abnormality (On MRI) respectively. Among 14 patients of grade $2 \mathrm{~K}-\mathrm{L}$ score, 1, 4, 4 and 5 patients had grade 2A, 2B, 3A and grade 3B Cartilage abnormality (On MRI) respectively. Among 2 patients of grade $3 \mathrm{~K}-\mathrm{L}$ score, both of these had grade 3B Cartilage abnormality (On MRI). Conclusion: MRI plays an important role in imaging the bony and soft tissues of knee as a whole organ, thereby helping in better management and outcome of the disease.

Keywords: Magnetic resonance imaging, Osteoarthritis, Radiographic findings.

Corresponding Author: Dr. Munish Kumar Garg, Junior Resident, Dept. of Radio diagnosis, Govt Medical College, Patiala.

Received: September 2019

Accepted:September 2019

\section{Introduction}

Osteoarthritis (OA) is a widely prevalent disease worldwide and is a major public health problem that primarily affects the elderly. The increasing importance of imaging in osteoarthritis for diagnosis, prognosis and follow-up is well recognized by both clinicians and osteoarthritis researchers. While conventional radiography is the gold standard imaging technique for the evaluation of known or suspected osteoarthritis in clinical practice and research. ${ }^{[1-3]}$ Radiography is still the most commonly used imaging modality for establishing an imaging-based diagnosis of OA But it has limitations that have become apparent in the course of large magnetic resonance imaging (MRI)-based knee osteoarthritis studies. ${ }^{[4]}$

Radiography is the simplest, least expensive and most commonly deployed imaging modality for OA. It enables detection of OA-associated bony features such as osteophytes, subchondral sclerosis and cysts. Radiography can also determine joint space width (JSW), which is a surrogate for cartilage thickness and meniscal integrity in knees, but direct visualization of these articular structures is not possible. OA is radiographically defined by the presence of marginal osteophytes. Worsening of JSN is the most commonly used criterion for the assessment of structural OA progression and the total loss of JSW ("bone-on-bone" appearance) is one of the indicators for joint replacement. ${ }^{[5,6]}$

It is a widely accepted fact that cartilage loss is not the only contributor to JSN but that changes in the meniscus such as meniscal extrusion and meniscal substance loss are also causative factors. The severity of radiographic OA can be assessed with semiquantitative scoring systems. The Kellgren and Lawrence (KL) grading system is a widely accepted scheme for defining radiographic OA based on the presence of a definite osteophyte (grade 2) ${ }^{[6]}$

Focal cartilage defects and bone marrow lesions are best assessed using fluid-sensitive fast spin echo sequences (e.g. T2-weighted, proton density-weighted or intermediateweighted) with fat suppression. ${ }^{[7-9]}$

Hence; the present study was undertaken to define the radiographic findings of osteoarthritis (OA) of knee joint using Kellgren-Lawrence scores and to define cartilage 
abnormalities on magnetic resonance (MR) imaging.

\section{Subjects and Methods}

Present study was conducted on 50 patients presenting with knee pain and clinical suspicion of osteoarthritis who were referred to the department of Radiodiagnosis, Rajindra hospital Patiala. Detailed radiographic and MR imaging was done in all subjects.Antero-posterior radiographs of the knee were obtained in a weight-bearing extended position by using a standard radiographic technique. All radiographs were assigned scores by using the Kellgren-Lawrence scoring system. This summary Kellgren-Lawrence score was based on osteophyte formation, joint space narrowing, sclerosis, and joint deformity characteristics according to the five-level scale defined as follows: grade 0, normal; grade 1, doubtful osteoarthritis; grade 2, minimal osteoarthritis; grade 3, moderate osteoarthritis; or grade 4, severe osteoarthritis.

\begin{tabular}{|l|l|l|}
\hline Grade & Classification & Description \\
\hline 0 & Normal & No radiographic features of osteoarthritis \\
\hline 1 & $\begin{array}{l}\text { Doubtful } \\
\text { Osteoarthritis }\end{array}$ & $\begin{array}{l}\text { Possible joint space narrowing (normal } \\
\text { joint space is at least 2mm) and osteophyte } \\
\text { formation }\end{array}$ \\
\hline 2 & $\begin{array}{l}\text { Minimal } \\
\text { Osteoarthritis }\end{array}$ & $\begin{array}{l}\text { Definite osteophyte formation with } \\
\text { possible joint space narrowing }\end{array}$ \\
\hline 3 & $\begin{array}{l}\text { Moderate } \\
\text { Osteoarthritis }\end{array}$ & $\begin{array}{l}\text { Multiple osteophytes, definite joint space } \\
\text { narrowing, sclerosis and possible bony } \\
\text { deformity }\end{array}$ \\
\hline 4 & $\begin{array}{l}\text { Severe } \\
\text { Osteoarthritis }\end{array}$ & $\begin{array}{l}\text { Large osteophytes, marked joint space } \\
\text { narrowing, severe sclerosis and definite } \\
\text { bony deformity }\end{array}$ \\
\hline
\end{tabular}

MR imaging of the knee was performed on Siemens magneto aera 1.5T MRI machine. Multiplanar MR imaging was performed in axial, coronal and sagittal planes as per the following protocol: PD fat suppressed Axial, sagittal and coronal view, T1WI sagittal view, T2WI sagittal view, T2WI space sagittal view.

Cartilages alterations were assigned grades as follows: grade 0 , normal; grade I, internal signal intensity alteration only; grade IIA, defect of cartilage of less than 50\%; grade IIB, defect of cartilage of 50\%-99\%; grade IIIA, $100 \%$ defect of cartilage with no bone ulceration; or grade IIIB, $100 \%$ defect of cartilage with subjacent bone ulceration.Radiographic and MR imaging findings were compiled as per performa and subjected to analysis using appropriate statistical tests.

\section{Results}

Table 1: Age-Wise Distribution of Patients
\begin{tabular}{|l|l|l|}
\hline Age Group(in years) & No. of Patients & $\%$ age \\
\hline$<40$ & 5 & 10 \\
\hline 40 to 50 & 6 & 12 \\
\hline 51 to 60 & 15 & 30 \\
\hline 61 to 70 & 12 & 24 \\
\hline$>70$ & 12 & 24 \\
\hline Total & 50 & 100 \\
\hline Mean \pm SD & $57.26 \pm 8.89$ & \\
\hline
\end{tabular}

Table 2: Distribution of Patients According To KellgrenLawrence Score (On Radiography)

\begin{tabular}{|l|l|l|l|}
\hline $\begin{array}{l}\text { Kellgren-Lawrence } \\
\text { Score } \\
\text { (on Radiography) }\end{array}$ & Parameter & $\begin{array}{l}\text { No. of } \\
\text { Patients }\end{array}$ & \%age \\
\hline Grade 0 & Normal & 26 & 52 \\
\hline Grade 1 & $\begin{array}{l}\text { Doubtful } \\
\text { Osteoarthritis }\end{array}$ & 8 & 16 \\
\hline Grade 2 & $\begin{array}{l}\text { Minimal } \\
\text { Osteoarthritis }\end{array}$ & 14 & 28 \\
\hline Grade 3 & $\begin{array}{l}\text { Moderate } \\
\text { Osteoarthritis }\end{array}$ & 2 & 4 \\
\hline Grade 4 & $\begin{array}{l}\text { Severe } \\
\text { Osteoarthritis }\end{array}$ & 0 & 0 \\
\hline Total & & 50 & 100 \\
\hline
\end{tabular}

Table 3: Comparison Of Distribution Of Patients According To Kellgren-Lawrence Score (On Radiography) And According To Cartilage Abnormality (On Mri)

\begin{tabular}{|c|c|c|c|c|c|c|}
\hline \multirow{2}{*}{$\begin{array}{l}\text { Cartilage } \\
\text { abnormality } \\
\text { (On MRI) }\end{array}$} & \multicolumn{4}{|c|}{$\begin{array}{l}\text { Kellgren-Lawrence score } \\
\text { (On Radiographic) }\end{array}$} & \multirow[t]{2}{*}{ Total } & \multirow{2}{*}{$\begin{array}{l}\text { Fisher's } \\
\text { Exact Test } \\
\text { p- value }\end{array}$} \\
\hline & $\begin{array}{l}\text { Grade } \\
0\end{array}$ & $\begin{array}{l}\text { Grade } \\
1\end{array}$ & $\begin{array}{l}\text { Grade } \\
2\end{array}$ & $\begin{array}{l}\text { Grade } \\
3\end{array}$ & & \\
\hline Grade 0 & 6 & 2 & 0 & 0 & 8 & \multirow{7}{*}{$\begin{array}{l}0.032 \\
\text { (Significant) }\end{array}$} \\
\hline Grade I & 4 & 0 & 0 & 0 & 4 & \\
\hline Grade II A & 6 & 2 & 1 & 0 & 9 & \\
\hline Grade II B & 4 & 2 & 4 & 0 & 10 & \\
\hline Grade III A & 4 & 2 & 4 & 0 & 10 & \\
\hline Grade III B & 2 & 0 & 5 & 2 & 9 & \\
\hline Total & 26 & 8 & 14 & 2 & 50 & \\
\hline
\end{tabular}

A total of 50 patients with OA were analysed. Mean age of the patients was 57.26 years. 26 patients $(52 \%)$ had grade 0 K-L score, 8 patients $(16 \%)$ had Grade 1 K-L score, 14 patients $(28 \%)$ had Grade $2 \mathrm{~K}-\mathrm{L}$ score, 2 patients $(4 \%)$ had Grade $3 \mathrm{~K}-\mathrm{L}$ score, while none of the patient had grade $4 \mathrm{~K}$ L score. Among 26 patients of grade $0 \mathrm{~K}-\mathrm{L}$ score, 6, 4, 6, 4, 4 and 2 patients had grade 0 , grade 1 , grade $2 \mathrm{~A}$, grade $2 \mathrm{~B}$, grade $3 \mathrm{~A}$ and grade $3 \mathrm{~B}$ Cartilage abnormality (On MRI) respectively. Among 8 patients of grade $1 \mathrm{~K}-\mathrm{L}$ score, 2, 2, 2 and 2 patients had grade 0 , grade $2 \mathrm{~A}$, grade $2 \mathrm{~B}$ and grade 3A Cartilage abnormality (On MRI) respectively. Among 14 patients of grade $2 \mathrm{~K}-\mathrm{L}$ score, 1, 4, 4 and 5 patients had grade 2A, 2B, 3A and grade 3B Cartilage abnormality (On MRI) respectively. Among 2 patients of grade $3 \mathrm{~K}-\mathrm{L}$ score, both of these had grade 3B Cartilage abnormality (On MRI).

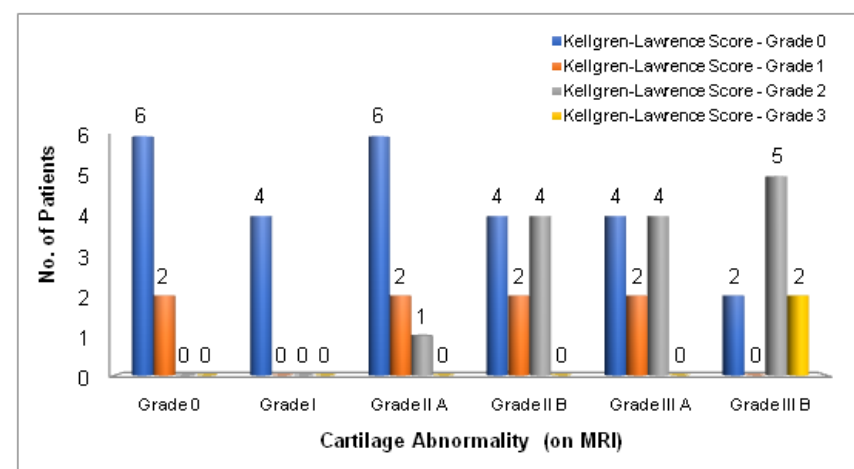

Graph 1: 


\section{Discussion}

The present study included 50 patients who had history of knee pain and clinical suspicion of Osteoarthritis of knee joint and underwent X-ray and MRI of the Knee Joint. Antero-posterior radiographs of the knee were obtained in a weight-bearing extended position by using a standard radiographic technique. All the scans were done using Siemens 1.5 Tesla High Gradient MRI scanner and using a scan protocol which included PD fat suppressed Axial, sagittal and coronal view, T1WI sagittal view, T2WI sagittal view, T2WI space sagittal view.

The study population consisted of patients of which 78 percent belonged to the age group of more than 50 years. Mean age of the patients was 57.26 years. 56 percent of the patients were females while 44 percent of the patients were males. Our results were in concordance with the results obtained by previous authors who also reported similar findings. Singh et $\mathrm{al}^{[9]}(2017)$ reported that 56.25 percent of OA patients in their study were of more than 50 years of age.

As reported in the past literature, about $13 \%$ of women and $10 \%$ of men aged 60 years and older have symptomatic knee OA. The proportions of people affected with symptomatic knee OA is likely to increase due to the aging of the population and the rate of obesity or overweight in the general population.A female predilection for occurrence of OA has also been reported in the past literature by $\mathrm{Pal}$ et $\mathrm{al}^{7}(2016)$ and Singh et $\mathrm{al}^{[8]}$ (2017).

The increase in the prevalence and incidence of OA with age probably is a consequence of cumulative exposure to various risk factors and biologic changes that occur with aging that may make a joint less able to cope with adversity, such as cartilage thinning, weak muscle strength, poor proprioception, and oxidative damage. Women not only are more likely to have OA than men, they also have more severe OA. The definite increase in OA in women around the time of menopause has led investigations hypothesize that hormonal factors may play a role in the development of OA..$^{[10,11]}$

In the present study, on MRI, $8(16 \%)$ patients had grade 0 (normal) cartilage abnormality, 4 patients (8\%) had Grade 1 cartilage defect (Intense signal intensity alteration), 9 patients (18\%) had Grade IIA abnormality (defect of cartilage less than 50\%) , 10 patients $(20 \%)$ had Grade IIB abnormality (defect of cartilage of $50 \%$ to $99 \%), 10$ patients (20\%) had Grade III A abnormality (100\% defect of cartilage with no bone ulceration) while 9 patients (18\%) had Grade III B abnormality $(100 \%$ defect of cartilage with subjacent bone ulceration). while on comparing this data with K-L score we found that among 26 patients of grade $0 \mathrm{~K}-\mathrm{L}$ score, $6,4,6,4,4$ and 2 patients had grade 0 , grade 1 , grade $2 \mathrm{~A}$, grade $2 \mathrm{~B}$, grade $3 \mathrm{~A}$ and grade 3B Cartilage abnormality (On MRI) respectively. Among 8 patients of grade $1 \mathrm{~K}-\mathrm{L}$ score, 2, 2, 2 and 2 patients had grade 0 , grade $2 \mathrm{~A}$, grade $2 \mathrm{~B}$ and grade 3A Cartilage abnormality (On MRI) respectively. Among 14 patients of grade $2 \mathrm{~K}-\mathrm{L}$ score, $1,4,4$ and 5 patients had grade $2 \mathrm{~A}, 2 \mathrm{~B}, 3 \mathrm{~A}$ and grade 3B Cartilage abnormality (On MRI) respectively. Among 2 patients of grade $3 \mathrm{~K}-\mathrm{L}$ score, both of these had grade 3B Cartilage abnormality (On MRI).

Our results were in concordance with the results obtained by Hayes et $\mathrm{al}^{[7]}$ (2005), who also reported similar findings in their study. They reported that $17.2 \%, 8.2 \%, 19.5 \%, 19.8 \%, 20.8 \%$ and $14.7 \%$ of the patients had normal, Grade I, Grade IIA, Grade IIB, Grade IIIA and Grade IIIB defect of cartilage.

MR imaging of the articular cartilage is particularly important, as articular cartilage degeneration is often cited as the structural hallmark of OA progression.A 2005 study by Amin et al. ${ }^{[6]}$ revealed that a significant number of symptomatic patients show cartilage loss on MRI even when joint space narrowing or disease progression is not visualized on radiography. In their study, radiographic progression was $91 \%$ specific but only $23 \%$ sensitive for cartilage loss.

MR technology has evolved to provide quantitative information about the physiological content of articular cartilage. These developments have been useful in identifying early damage and breakdown. In OA, proteoglycan and collagen content are reduced. This disrupts the collagen network and results in increased water content and matrix degradation. Newer methods of MRI exploit these macromolecule changes to provide a quantitative understanding of the breakdown process. In general, fat suppression is useful in cartilage imaging because it results in a higher dynamic range of signal intensities in the articular cartilage and reduces or eliminates chemical shift artifacts. ${ }^{[12,13]}$

\section{Conclusion}

Osteophytes develop at an earlier stage than joint space narrowing, and they are the most widely applied radiographic criterion for defining the presence of OA. MRI plays an important role in imaging the bony and soft tissues of knee as a whole organ, thereby helping in better management and outcome of the disease.

\section{References}

1. Hayashi D, Roemer FW, Guermazi A. Imaging for osteoarthritis. Annals of Physical and Rehabilitation Medicine. 2016;59(3):161-9.

2. Menashe L, Hirko K, Losina E, Kloppenburg M, Zhang W, Li L, Hunter DJ. The diagnostic performance of MRI in osteoarthritis: a systematic review and meta-analysis.Osteoarthritis Cartilage. 2012;20(1):13-21.

3. Guermazi A, Hayashi D, Roemer F, Felson DT, Wang K, Lynch J et al. Severe radiographic knee osteoarthritis - does Kellgren and Lawrence grade 4 represent end stage disease? Osteoarthritis Cartilage. 2015;23:1499-505.

4. Guermazi A, Niu J, Hayashi D, Roemer FW, Englund M, Neogi T et 


\section{Sahni et al; Assessment of Carrelation of Radiagraphic Findings and Cartilage Clenarmalities an MRI in}

\section{Ostecarthritis Fnee Patients}

al. Prevalence of abnormalities in knees detected by MRI in adults without knee osteoarthritis: population based observational study (Framingham Osteoarthritis Study). BMJ. 2012;345:e5339.

5. Guermazi A, Roemer FW, Haugen IK, Crema MD, Hayashi D. MRIbased semiquantitative scoring of joint pathology in osteoarthritis. Nat Rev Rheumatol 2013;9:236-51.

6. Amin S, LaValley MP, Guermazi A, Grigoryan M, Hunter DJ, Clancy $\mathrm{M}$ et al. The relationship between cartilage loss on magnetic resonance imaging and radiographic progression in men and women with knee osteoarthritis. Arthritis Rheum. 2005;52(10):3152-9.

7. Hayes CW, Jamadar DA, Welch GW, Jannausch ML, Lachance LL, Capul DC et al. Osteoarthritis of the knee: comparison of MR imaging findings with radiographic severity measurements and pain in middle-aged women. Radiology. 2005;237(3):998-1007.

8. Pal CP, Singh P, Chaturvedi S, Pruthi KK, Vij A. Epidemiology of knee osteoarthritis in India and related factors. Indian J Orthop.

\section{6;50(5):518-22}

9. Singh AK, Sharma V, Senger KPS, Singh A, Prateek. Degenerative disease of knee joint: a clinico-radiological correlation. IntSurg J 2017;4:866-73.

10. Zhang Y, Jordan JM. Epidemiology of osteoarthritis. ClinGeriatr Med. 2010;26(3):355-69.

11. Sowers M. Epidemiology of risk factors for osteoarthritis: systemic factors. Current Opinion in Rheumatology. 2001;13(5):447-51.

12. Dijkgraaf LC, de Bont LG, Boering G, Liem RS. The structure, biochemistry, and metabolism of osteoarthritic cartilage: a review of the literature. J Oral Maxillofac Surg. 1995;53:1182-92.

13. Roemer FW, Crema MD, Trattnig S, Guermazi A. Advances in Imaging of Osteoarthritis and Cartilage. Radiology.2011;260(2): 332- 54 .

Copyright: (C) the author(s), publisher. Asian Journal of Medical Radiological Research is an Official Publication of "Society for Health Care \& Research Development". It is an open-access article distributed under the terms of the Creative Commons Attribution Non-Commercial License, which permits unrestricted non-commercial use, distribution, and reproduction in any medium, provided the original work is properly cited.

How to cite this article: Sahni G, Kumar S, Garg MK, Jain AK. Assessment of Correlation of Radiographic Findings and Cartilage Abnormalities on MRI in Osteoarthritis Knee Patients. Asian J. Med.Radiol.Res. 2019;7(2):109-112.

DOI: dx.doi.org/10.21276/ajmrr.2019.7.2.23 